\title{
BUDAYA NASIONAL DI TENGAH PASAR: KONSTRUKSI, DEKONSTRUKSI, DAN REKONSTRUKSI
}

\author{
Ikwan Setiawan \\ Jurusan Sastra Inggris Universitas Jember Jawa Timur \\ Email: setyokultura@yahoo.com
}

\begin{abstract}
In the Reformation period, the state regime still mobilizes traditional-ideal values as national culture without giving conceptual and operational explanations. In this article, I combine two approaches, cultural studies and postcolonial studies, for reading national culture as represented in some President Soesilo Bambang Yudhoyono's presidential speeches. I will analyze ideal-but-ambivalent constructions of national culture in regime's perspective as represented in those speeches, particularly, in the context of continuous of national culture in regime's perspective in those speeches, particularly, in the context of the government's continuous mobilization of traditional meanings as the invisible power for Indonesian people, while, at the same time,placing emphasis on economic progress.Instead of a strategic cultural construction, national culture produces its own deconstruction and fails to be discursive formation. Further, I argue that the regime operates their governmentality by reconstructing newer national culture based on market economics as discursive constructions, which ideally can provide conceptual and material basis for state regime in conducting governance and for citizens in achieving welfare in neoliberal formation.
\end{abstract}

Keywords: National Culture, Regime's Perspective, Construction, Deconstruction, Reconstruction, Neoliberalism.

\begin{abstract}
ABSTRAK
Pada masa Reformasi, rezim negara masih memobilisasi nilai-nilai tradisional-ideal sebagai budaya nasional tanpa memberikan penjelasan konseptual dan operasional. Dalam artikel ini, saya menggabungkan dua pendekatan, kajian budaya dan poskolonial, untuk membaca budaya nasional sebagaimana direpresentasikan dalam beberapa pidato Presiden Soesilo Bambang Yudhoyono. Saya akan menganalisis konstruksi ideal-tetapi-ambivalen dari budaya nasional dalam perspektif rezim seperti direpresentasikan dalam beberapa pidato tersebut, khususnya, dalam konteks mobilisasi terus-menerus makna tradisional sebagai kekuatan tidak kelihatan bagi rakyat Indonesia, sedangkan pada saat bersamaan, mereka selalu menekankan kemajuan ekonomi. Alih-alih sebagai konstruksi kultural strategis, budaya nasional memproduksi dekonstruksinya sendiri dan gagal menjadi formasi diskursif. Lebih jauh, saya berargumen bahwa rezim menjalankan kepemerintahan mereka dengan merekonstruksi budaya nasional baru berbasis ekonomi pasar sebagai konstruksi diskursif yang secara ideal bisa menyediakan basis konseptual dan material bagi rezim untuk menjalankan pemerintahan dan bagi warga negara untuk memperoleh kesejahteraan dalam formasi neoliberal.
\end{abstract}

Kata Kunci: Budaya Nasional, PerspektifRezim, Konstruksi, Dekonstruksi, Rekonstruksi, Neoliberalisme. 


\section{PENGANTAR}

Dalam Orasi Kebudayaan yang dilaksanakan padaDies Nataliske-30Universitas Diponegoro, 30 Oktober 2008, Presiden Susilo Bambang Yudhoyono (selanjutnya disingkat Presiden SBY) mengatakan:

Sejak Indonesia merdeka, bukan main tantangan, ujian, dan cobaan yang kita hadapi...Tetapi mengapa kita selamat, mengapa kita akhirnya bisa mengatasi, mengapa kita tidak runtuh?... Karena ada satu kekuatan, yang barangkali kita tidak sadari. Apa kekuatan itu, yaitu kebangsaan kita, ke-Indonesia-an kita, ketahanan kita, karakter kita sebagai pejuang, sikap tidak mengenal menyerah, dan sebagainya. Inilah yang saya katakan kekuatan, the power, the strength yang bersumber dari budaya bangsa, dahsyat. Ini boleh disebut the invisible power, kekuatan yang tidak kentara, dibandingkan kekuatan sumber daya alam, sumber daya keuangan, sumber daya manusia, dan sebagainya...The invisible power of culture...saya mengajak Saudara semuanya, marilah budaya sebagai sumber, sebagai energi, sebagai kekuatan ini kita jadikan pula untuk membangun bangsa kita di masa depan. (penekanan saya)

"Budaya" dalam perspektif Presiden SBY merupakan the invisible power-kekuatan tidak kentara/kelihatan-yang menjadi sumber kekuatan, energi, dan daya tahan untuk membangun Indonesia. Kekuatan tersebut merupakan "nilai-nilai unggul" berupa kebangsaan kita, ke-Indonesia-an kita, ketahanan kita, karakter kita sebagai pejuang, dan sikap tidak mengenal menyerah. Pilihan menempatkan budaya sebagai "kekuatan yang tidak kentara" dapat menghadirkan ambiguitas. Di satu sisi, budaya diposisikan sebagai kekuatan adikodrati yang sewaktuwaktu bisa dipanggil kembali ketika bangsa ini membutuhkannya. Di sisi lain, budaya merupakan bentuk jati diri esensialis dan retrospektif (klangenan) yang diidealisasi sebagai konsensus, sementara globalisasi dan neoliberalisasi telah, sedang, dan akan terus menawarkan ragam kultural baru.
Dalam pandangan ini bahwa ambiguitas memunculkan ketidakjelasan konseptual dan material konstruksi "budaya nasional" sebagai kekuatan bangsa, sejak rezim Soekarno, Soeharto, sampai dengan SBY. Budaya nasional bersendi kearifan lokal masih dibayangkan ada, tetapi masih sebatas slogan pemanis. Kalaupun budaya nasional diposisikan sebagai "puncak-puncak kebudayaan daerah", "nilai-nilai unggul", dan "kekuatan strategis bangsa", konstruksikonstruksi itu tidak pernah dijelaskan, sehingga tidak pernah mewujud sebagai formasi diskursif yang mampu memperkuat kesadaran nasional.

Dalam tulisan ini, pembacaan secara kritis ketidakjelasan diskursif budaya nasional dalam perspektif rezim negara sebagaimana direpresentasikan dalam beberapa naskah pidato Presiden SBY. Dengan menggunakan perspektif cultural studies dan kajian poskolonial, maka analisis ini menggunakan analisis wacana tentang budaya nasional yang dilontarkan Presiden SBY sebagai konstruksi yang mengidealisasi kekuatan kultural bangsa sebagai rezim kebenaran. Namun, konstruksi tersebut, pada dasarnya, memunculkan ketidakstabilan dari awal karena masih mengutamakan konsep esensialis dan retrospektif. Dengan perspektif dekonstruksi Derridean bahwa pembacaan budaya nasional sebagai konstruksi yang dipenuhi "penghancuran" dari dalam sehingga gagal menjadi formasi diskursif di tengah-tengah kompleksitas kultural masyarakat. Proses dekonstruksi tersebut, pada akhirnya, menghasilkan rekonstruksi "budaya nasional baru" dalam jejaring ekonomi-politik yang lebih berorientasi kepada ekonomi pasar.

\section{PEMBAHASAN \\ Membincang-Ulang Budaya Nasional}

Fanon (1963: 233) secara visioner mengingatkan masyarakat di negara-negara pascakolonial terkait konstruksi budaya 
nasional yang seharusnya dikonstruksi sebagai "segenap usaha" dalam bentuk "pemikiran" untuk menciptakan dan memperjuangkan "eksistensi diri". Bukanlah mitos, tradisi lisan, ataupun kekuatan adikodrati yang bisa mendorong lahirnya budaya nasional, tetapi pemikiran-pemikiran strategis berbasis realitas - permasalahan dan kekuatan riil yang dimiliki masyarakat. Dengan demikian, budaya nasional bukan berhenti sebagai konsep-konsep abstrak populis - slogan dan propaganda, misalnya. Ia merupakan sesuatu yang berada dalam "proses menjadi" yang akan menghasilkan nilai, konsep, dan tindakan baru bagi keseluruhan masyarakat.

Penekanan rasionalitas dalam budaya nasional menunjukkan bahwa orientasi bagi kemajuan bangsa menuntut adanya pikiranpikiran modern yang akan menjadi identitas kolektif dan memperkuat nasionalisme. Dalam perspektifGellner, menguatnya normanorma kultural baru berbasis modernitas pada pendidikan, teknologi komunikasi, birokrasi, dan struktur negara modern digerakkan oleh aturan-aturan rasionalistis serta administratif akan mendorong lahirnya nasionalisme yang melampaui batasanbatasan etnis (Edensor, 2002: 3; Spencer \& Wollman, 2002: 36; Gandhi, 1998: 104-105). Memang, menguatnya rasionalitas dan birokrasi modern menyebabkan kekayaan kultural etnis sebagai identitas masyarakat menempati posisi marjinal, meskipun tidak bisa dikatakan hilang-budaya residual. Nasionalisme berbasis modernitas di negaranegara pascakolonial ternyata menyebabkan ambivalensi, keberantaraan, dan kegandaan kultural yang terus berlanjut hingga saat ini (Faruk, 2007: 9; Mbembe, 2001: 12; Quayson, 2000: 16-17). Di satu sisi, nasionalisme menuntut kehadiran nilai-nilai kultural baru berorientasi kesamaan, rasionalitas, dan kebebasan yang berujung kepada kesejahteraan, bukannya mitos, dongeng, kuasa agama, maupun tradisionalisme lainnya. Di sisi lain, budaya residual berbasis etnis masih dianggap penting untuk membangun solidaritas kebangsaan untuk melawan kekuatan-kekuatan asing yang dianggap membahayakan bagi kepentingan nasional.

Dalam pandangan Bhabha (1994) masyarakat pascakolonial di tengah-tengah ambivalensi kultural bisa memunculkan strategi subjektivitas tanpa harus meninggalkan sepenuhnya nilai dan identitas kultural tradisional sekaligus tidak mengambil sepenuhnya yang modern-hibriditas. Praktik tersebut bisa menjadi kekuatan untuk memaknai-ulang jejak kuasa kolonial dan superioritas Barat (Radhakrisnan, 2003: 1-2), tetapi bisa juga menjadi tindakan yang menyulitkan ketika masyarakat sulit melepaskan diri dari bayang-bayang kuasa Barat (Gandhi, 1998: 5-7). Subjektivitas pascakolonial yang diwarnai keberantaraan dan hibriditas itulah yang menyebabkan proses kultural bersifat kompleks. Konstruksi budaya nasional tentu membutuhkan ketepatan dan kecerdasan dalam memaknai realitas keberantaraan kultural.

Pola pikir transformatif merupakan pilihan strategis untuk dilakukan. Aschroft (2000: 1) menjelaskan transformasi sebagai modal berpikir dan bertindak pada masyarakat yang terjajah atau terdominasi mentransformasi kekuatan-kekuatan kultural yang mendominasi mereka untuk memberdayakan diri dan mengendalikan masa depan. Para elit politik di negara pascakolonial semestinya secara cerdas meng-apropriasi sebagian budaya modern dan menegosiasikan kearifan lokal yang akan disepakati menjadi konstruksi budaya nasional. Ketika budaya nasional telah dikonstruksi, para elit politik harus terus menyebarkannya sebagai formasi diskursifmengikuti pemikiran Foucauldian (Foucault, 2002: 52-58; Hall, 1997: 44) -dalam bahasa/ representasi dan praksis rakyat kebanyakan. Dalam terma Foucauldian (Foucault, 2008; Collier, 2009; McNay, 2009), budaya nasional 
bisa menjadi mekanisme pendisiplinan dan kepemerintahan-dalam makna produktifyang bisa memperbaiki kehidupan berbangsa. Dengan perspektif tersebut, budaya nasional secara ajeg perlu dievaluasi, dikritik, dan direkonseptualisasi.

Sayangnya, para elit politik seringkali sekedar mengambil nilai-nilai stereotip berbasis etnis, moral, atau agama untuk digunakan sebagai konsep budaya nasional. Akibatnya, budaya nasional menjadi kebijakan yang bersifat (1) konservatif, (2) tertutup terhadap ketidakpuasan masyarakat, dan (3) tidak mengakomodir kesadaran kultural posmodern masyarakat yang mengutamakan pemenuhan selera kulturaldiri dan tidak menerima konsep kultural yang sudah mapan (McGuigan, 1996: 50). Budaya nasional menjadi kaku, tidak transformatif, dan represif. Tidak mengherankan, ketika mekanisme pasar memberikan keleluasaan pilihan kultural baru yang serba cepat dan beragam, konstruksi budaya nasional akan mengalami kegagapan karena hanya menjadi slogan konservatif rezim yang, ironisnya, juga larut dalam kuasa neoliberalisme.

\section{Budaya Nasional Di Masa Reformasi: Konstruksi dan Dekonstruksi}

Gerakan Reformasi secara politik memang membawa perubahan ke arah kehidupan yang lebih transparan dan demokratis, tetapi secara ekonomi memasukkan Indonesia ke dalam jejaring neoliberalisme. Kebijakan neoliberal secara umum berbentuk (1) pengurangan campur-tangan negara dalam sektor ekonomi-termasuk swastanisasi BUMN dan pengutamaan mekanisme pasar, (2) optimalisasi peran swasta, dan (3) deregulasi kebijakan sosial (Clarke, 2005: 50-51; Palley, 2005: 20-24; Harvey, 2007: 64-87; England \& Ward, 2007:12). Namun demikian, perubahanperubahan tersebut belum berpengaruh pada perubahan paradigma rezim negara terhadap budaya nasional. Mereka masih mengkonstruksi budaya nasional sebagai nilai-nilai dan jati diri bangsa yang harus dijaga di tengah-tengah perubahan sosial, ekonomi, dan politik saat ini.

Dalam pidato sambutannya pada Kongres Persatuan Artis Film Indonesia XIII, 18 Mei 2006, Presiden SBY menegaskan:

Salah satu bagian dari kebudayaan... adalah film Indonesia. Film...dapat menjadi media untuk mempertinggi derajat dan martabat seni dan budaya bangsa kita. Film...dapat menjadi bagian dari pilar kebudayaan, menumbuhkan ruang dialog yang kreatif dan memelihara kemajemukan budaya bangsa. Film, jangan hanya dijadikan tontonan penghibur saja, tetapi jadikanlah sebagai karya cipta seni budaya yang dapat menampilkan...karakter budaya...Sayamengajak seluruh pecinta film nasional, mendorong setiap upaya produksi film yang dapat memperkuat nilai-nilai dan jati diri budaya bangsa kita... Saya mengajak para insan film untuk lebih banyak menampilkan karya-karya sinema yang mengangkat etika, harkat dan martabat serta budaya bangsa kita. Kurangilah pembuatan filmfilm yang menampilkan kekerasan, kriminalitas dan pornografi, apalagi film-film yang dapat merusak akhlak dan moral bangsa kita...Saya berharap, para sineas muda memiliki komitmen yang kuat untuk mengedepankan nilai-nilai budaya kita dalam karya-karyanya...Marilah kita jadikan film nasional sebagai media yang dapat menyampaikan pesan-pesan moral dan mempromosikan keanekaragaman serta kekayaan budaya yang kita miliki. (penekanan saya)

Pidato tersebut menunjukkan keberlanjutan paradigma esensialis dan retrospektif dalam memandang budaya nasional oleh rezim negara. Budaya nasional masih diposisikan sebagai konsepsi ideal- "nilai-nilai" dan "jati diri" - yang disejajarkan dengan karakter, harkat, etika, dan martabat bangsa serta perlu menjadi acuan kolektif bagi tingkah laku, pemikiran, dan eskpresi, termasuk produksi film. Ajakan Presiden SBY kepada artis film dan sineas (subjek) untuk memperkuat dan menyebarkan budaya bangsa melalui film (teknologi tanda populer) memang strategis. Bennet (2005: 83) 
dengan perspektif Foucauldian menjelaskan budaya dalam perspektif kepemerintahan seharusnya disebarkan sebagai formasi diskursif melalui mobilisasi makna dan pengetahuan yang ditopang teknologi tanda, kesiapan teknik, dan ragam aparat. Namun, Presiden SBY dan juga aparat negara lainnya tidak memperjelas kontekstualisasi budaya bangsa dalam produksi film, sehingga ia menjadi konstruksi konservatif yang menghalangi kebebasan berekspresi dan, pada level tertentu, menghadirkan resistensi. Gerakan Masyarakat Film Indonesia (MFI) yang menuntut reformasi aturan perfilman nasional, termasuk pembubaran Lembaga Sensor Film, karena dianggap memangkas kebebasan dan kreativitas para sineas dalam berkarya dengan argumen moralitas dan budaya bangsa merupakan contoh konkrit dari resistensi tersebut (Indarto, 2007a, 2007b; Arsuka, 2008; Wardhana, 2008).

Dengan mengkonstruksi budaya nasional berbasis nilai-nilai restropektif, rezim negara berusaha mengarahkan masyarakat untuk tetap mengedepankan nilai dan praktik tradisional yang digeneralisasi masih hidup di tengah-tengah kehidupan transaksional mereka. Gotong-royong, misalnya, masih diposisikan sebagai nilai dan praktik ideal yang harus terus dipertahankan. Bahkan, pemerintah meneruskan program Gerakan Nasional Bulan Bhakti Gotong Royong yang pada tahun 2011 memasuki tahun ke-8 dan pencanangannya dilaksanakan di Pontianak, 31 Mei 2011. Presiden SBY dalam pidato sambutannya mengatakan:

...saya ingin menyampaikan pesan dan ajakan khusus...yang pertama adalah dalam era reformasi...era demokratisasi dan...era globalisasi apalagi kita kaitkan dengan hajat kita hari ini, dengan falsafah dan budaya gotong royong dan kebersamaan sosial... maka sekali lagi pesan dan ajakan saya jangan tinggalkan jati diri, nilai dan kepribadian bangsa. Jangan menjadi bangsa lain, kita tetap bangsa Indonesia, manusia Indonesia. Jangan dibuang dan dianggap tidak perlu tata karma, budi pekerti dan sikap saling hormat menghormati di antara warga bangsa karena itulah jati diri bangsa Indonesia. Jangan diremehkan atas nama reformasi, demokratisasi dan globalisasi yang namanya paguyuban, kerukunan sosial dan kearifan lokal. (penekanan saya)

Manusia Indonesia dalam imajinasi rezim negara semestinya adalah individu yang terus mengutamakan tata krama, gotong royong, budi pekerti, kesetiakawanan sosial, kerukunan, kesopanan, dan kearifan lokal. Konsepsi-konsepsi tradisional tersebut memang bersifat strategis di tengah-tengah orientasi kesejahteraan berbasis ekonomi pasar yang mengedepankan kompetisi dan invidualisme. Saya melihat Presiden SBY berusaha mengkonstruksi subjektivitas antara di tengah-tengah keberantaraan dan kompleksitas kultural pada era Reformasi, demokratisasi, dan globalisasi. Artinya, rezim negara berusaha berpikir transformatif dan tidak selalu terjebak dalam paradigma biner yang dipenuhi ketegangan kultural ketika memposisikan "yang tradisional" dan "yang modern"; menjalankan sebagian kekuatan tradisional, sembari menikmati kemajuan

Subjektivitas antara yang berasal dari penyikapan keberantaraan kultural itulah yang diasumsikan rezim negara bisa menjadi kunci kemajuan Indonesia. Dalam lanjutan pidatonya SBY mengatakan:

Ingat Saudara-saudara, kebebasan tanpa batas, mendewakan kebebasan, menganggap kebebasan itu Tuhan, lantas membuang kearifan termasuk kearifan lokal, etika dan tata karma itu bukan jati diri dan kepribadian bangsa Indonesia, bukan. Bangsa-bangsa lainpun yang menganut faham demokrasi yang liberal sekalipun mereka juga tetap ada etikanya, tata karma dan penghormatan terhadap kearifan lokal. Mari kita menjadi manusia Indonesia, masyarakat Indonesia, bangsa Indonesia meskipun kedepan menjadi bangsa yang maju dan modern...Kita jangan silau dengan reformasi, demokratisasi dan globalisasi lantas keluar dari jati diri, nilai kepribadian, perilaku dan etika kita sebagai bangsa. Sedangkan yang kedua...ajakan, harapan dan pesan saya 
adalah juga dalam era reformasi, demokratisasi dan globalisasi janganlah ditinggalkan, dihina dan diremehkan pentingnya kesetiakawanan sosial, kerukunan masyarakat dan budaya gotong royong. (penekanan saya)

Secara imperatif sekaligus persuasif, SBY memberikan wejangan (nasehat) bahwa masyarakat Indonesia seyogyanya tidak "mendewakan atau menuhankan kebebasan" dan "membuang kearifan lokal". Kebebasan yang menjadi kunci utama modernitas (Venn, 2006: 55-57, 2000: 17-19; McGuigan, 1999: 40-41) dimaknai-ulang sebagai 'kebebasan bersyarat' yang harus tetap memasukkan kearifan lokal yang nota-bene tidak menerima kebebasan mutlak. Indonesia modern dalam idealitas rezim negara adalah Indonesia yang masih meyakini dan menjalankan kearifan lokal di tengah-tengah usaha menuju "negara dan bangsa maju". Dalam pemikiran Bhabha \& Comaroff (2002: 24) kondisi ideal itu disebut vernacular cosmopolitanism, di mana dengan prinsip hibriditas masyarakat pascakolonial mendekonstruksi aspek-aspek modernitas tanpa harus mengedepankan "kedaulatan dan kebebasan liberal" serta tetap memasukkan aspek-aspek tradisional"yang lampau" dalam "yang kontemporer", atau mengikuti pemikiran Canclini (1995), "memasuki modernitas untuk kemudian meninggalkannya" karena pilihan menjalani hibriditas kultural berarti tetap memasukkan sebagian "yang tradisional" ke dalam "yang modern" - menjadi tidak sepenuhnya modern, tidak sepenuhnya tradisional.

Konstruksi budaya nasional dalam konteks pola pikir dan tindakan yang secara ajeg menegosiasikan kearifan lokal sembari mengartikulasikan modernitas, sebenarnya bisa menjadi kekuatan bangsa di tengahtengah globalisasi. Di akui atau tidak, globalisasi saat ini menjadi formasi dan praktik diskursif yang menghadirkan ragam nilai dan praktik kultural baru di ruang nasional/lokal (Banerjee, 2002: 519-520; Wise, 2008: 34-35).
Menegosiasikan kekuatan kultural bangsa secara esensial untuk menghadapi pengaruh globalisasi memang bisa menjadi pilihan strategis. Pilihan itulah yang oleh Spivak (dikutip dalam Morton, 2007: 126) disebut esensialisme strategis:

Jika seseorang menimbang strategi, maka ia harus melihat di mana sebuah kelompok - orang, orangorang, ataupun gerakan - disituasikan ketika ia membuat klaim-klaim untuk atau melawan esensialisme. Sebuah strategi menyesuaikan dengan situasi; sebuah strategi bukanlah teori.... Kegunaan strategi esensi sebagai slogan atau kata-utama yang dimobilisasi seperti perempuan atau pekerja atau nama bangsa secara ideal menjadi kesadaran-diri bagi mereka yang dimobilisir.

Mobilisasi jati diri, karakter, maupun martabat bangsa secara strategis memang bisa digunakan untuk menghadapi pengaruh ragam budaya dan kuasa asing yang masuk melalui ekonomi pasar. Namun, "kesadarandiri" dari semua subjek, termasuk aparat rezim, dan warga negara sangat dibutuhkan agar esensialisme kultural tersebut bisa berhasil. Fase kesadaran-diri tersebut membutuhkan keliatan dan kecerdasan untuk menjadikan "yang esensial" sebagai formasi dan praktik diskursif yang mampu menggerakkan kinerja kepemerintahan dan kehidupan sehari-hari masyarakat. Selain itu, kearifan lokal juga perlu terus dibacaulang agar bisa menemukan pemaknaanpemaknaan baru yang bersifat transformatif dan tidak sekedar menguntungkan para elit, baik di tingkat nasional maupun lokal.

Nilai-nilai komunalisme, seperti gotong-royong, saling menghormati, tolongmenolong, maupun toleransi, yang selama ini dianggap sebagai kearifan lokal masyarakat Indonesia memang tampak sangat ideal untuk dijadikan orientasi kolektif di tengah-tengah berkembangnya individualisme. Namun, realitas perubahan makna dari kearifankearifan tersebut tentu perlu diperhatikan 
dan dikritisi. Dalam masyarakat desa, misalnya, gotong-royong semakin jarang dilakukan. Kerja bersama dalam membangun rumah atau mengerjakan sawah yang dulu menjadi penanda kultural masyarakat desa, saat ini telah menjadi pekerjaan berupah. Kalaupun masih ada, gotong-royong hanya sebatas pada aktivitas publik, seperti bersihbersih saluran air dan menguburkan orang meninggal. Tragisnya, banyak korupsi yang terjadi dalam penyelenggaraan negara juga dilakukan secara gotong-royongdalam artian melibatkan banyak pihak yang bekerjasama untuk mengambil kuntungan ekonomi dengan cara jahat. Demikian pula sikap saling menghormati dan toleransi yang saat ini harus dipertanyakan-kembali ketika kekerasan yang mengatasnamakan agama konstalasinya semakin meningkat.

Sayangnya, dengan memobilisasi konsepsi kearifan lokal sebagai jati diri dan karakter budaya bangsa tanpa memberikan penjelasan diskursif, rezim negara sebenarnya mengedepankan esensialisme kultural secara mentah-mentah; tanpa melakukan kritik, pembacaan-ulang, dan rekonseptualisasi. Budaya bangsa, mengikuti pemikiran politik identitas, diposisikan sebagai identitas yang mengikat keseluruhan anggota masyarakat (Alcoff \& Mohanty, 2006: 6) sekaligus sebagai kekuatan dan strategi subjektivitas untuk bisa bertahan di tengah-tengah perubahan kultural dan relasi-relasi kuasa di dalamnya (D'Cruz, 2008: 2; Sawyer, 2006: 75). Namun, konsepsi tersebut juga bertentangan dengan fakta transformasi dan perubahan kultural serta bisa dieksploitasi untuk kepentingan kelas atau elit tertentu guna melegitimasi otoritasnya atas nama budaya (Gimenez, 2006: 431-432). Mobilisasi kearifan lokal tanpa menimbang realitas perubahan dalam masyarakat hanya akan menghasilkan "eksploitasi penanda" yang tidak akan memunculkan kesadaran-diri dan subjektivitas antara yang kuat. Ketika masyarakat disibukkan oleh aktivitas produktif di tengah-tengah mekanisme ekonomi pasar saat ini, kekuatankekuatan lokal yang masih dianggap ada itu semestinya direpresentasikan ke dalam wacana dan program yang mampu menjawab permasalahan yang dihadapi mereka.

Pikiran dan tindakan yang lebih masuk akal adalah bersiasat secara liat, terus menegosiasikan gagasan-gagasan tentang kearifan lokal yang sudah dimaknai-ulang sembari mengartikulasikan aspek-aspek modernitas yang juga sudah ditransformasi. Maka, mengikuti pemikiran Hall (1990: 22325) tentang identitas kultural, budaya nasional harus dikonsepsikan sebagai proses yang terus menjadi -memposisikan subjektivitas antara dalam narasi ke-masa-lampau-an - tanpa melupakan fakta perubahan yang dibawa modernitas. Gotong royong, misalnya, bisa dikonsepsikan sebagai kekuatan lokal untuk mengurangi angka kemiskinan dengan menciptakan usaha-usaha produktif yang dikelola secara bersama-sama oleh masyarakat dengan prinsip keterbukaan.

Rezim tentu harus mendukung aktivitas yang demikian melalui dukungan-dukungan finansial dan pendampingan yang benarbenar diorientasikan bagi pemberdayaan masyarakat. Ketika kearifan lokal bisa disiasati, dimaknai-ulang, dan direproduksi secara ajeg melalui beragam wacana dan praktik modern, maka mereka akan menjadi kekuatan yang menuntun gerak bangsa ke depan. Tanpa siasat untuk menemukan aspek-aspek strategis dalam keberantaraan kultural yang berlangsung, konstruksi budaya nasional secara esensialis hanya akan terdekonstruksi oleh (1) saling-selip konsep dan pemaknaan yang ada di dalamnya; (2) kontradiksi-kontradiksi berlanjut dari praktik dan permasalahan sosial terkait kearifan lokal; dan, (3) kuatnya kuasa pasar.

\section{Rekonstruksi Budaya Nasional Baru Berbasis Ekonomi Pasar}

Ketika secara diskursif, rezim negara tidak mampu mengkonstruksi budaya nasional 
yang bersifat konseptual dan operasional dalam menyelenggakaran kerja-kerja kepemerintahan dan kehidupan sehari-hari warga negara, maka yang terjadi adalah kegagalan dalam membangun "konsensus nasional baru" untuk menghadapi dan menyiasati perubahan kultural sebagai akibat menguatnya neoliberalisme. Pengaruh diskursif makna-makna kultural terkait neoliberalisme semakin menyebar dikarenakan (a) kuatnya pemodal swasta dan kendornyakontrol negara dalamindustribudaya dan (b) berkembang pesatnya media hiburan berbasis teknologi yang memperluas sirkuit pemuas hasrat sekaligus memobilisasi makna ideologis kapitalisme pasar (Hesmondhalgh, 2008: 101; Curran, 2002: 198-199; Hall, 2000; Kellner, 2003).

Bagaimanapun juga, masyarakat -dari petani, buruh, pelajar/mahasiswa, akademisi, hingga para pekerja industri budayasemakin terbiasa dengan ideologi pasar dan lalu-lintas budaya asing, meskipun mereka juga masih menjalankan sebagian nilai-nilai tradisional. Ketika mereka dihadapkan lagi pada konstruksi esensialis budaya nasional sebagaimana diyakini rezim-rezim sebelumnya, maka resistensiakan berkembang karena yang mereka butuhkan adalah sebuah konstruksi budaya nasional baru di tengahtengah pertumbuhan ekonomi pasar sebagai keberlanjutan proyek serupa di masa Orde Baru. Dalam kondisi tersebut, posisi diskursif nilai-nilai tradisional seperti gotong royong, kesetiakawanan, dan tata krama, memang tampak hanya menjadi pelengkap karena orientasi ekonomi pasar, kemajuan, dan kesejahteraan lebih menjanjikan bagi bangsa ini. Ternyata, rezim negara memang lebih cerdas untuk menjelaskan secara konseptual dan operasional pentingnya ekonomi pasar bagi kehidupan masyarakat.

Presiden SBY dalam lanjutan pidatonya dalam Kongres PARFI XIII, rupa-rupanya sangat sadar "pentingnya pasar" dalam industri film sebagai bentuk ekspresi kultural yang masih diminta mengedepankan karakter dan jati diri bangsa:

Maka, terhadap pasar yang sudah ada, bagaimana film kita ini menjadi a must seen movie. Artinya, pasar itu senang, cocok, tertarik dengan film... yang kita sajikan...Bisa judulnya baik. Bisa juga skenarionya baik. Bisa juga kekuatan dari artis-artisnya, bisa juga dengan bahasanya yang pas dengan market itu...kalau film...cocok untuk pasar, tanpa meninggalkan idealisme, tanpa meninggalkan nilai dan moralitas, maka pasarnya ada, movie yang kita bikin dibeli oleh pasar itu. Mari ke depan ini, kita konsentrasi apa yang diinginkan pasar. Kita lakukan penelitian, di Indonesia, di Malaysia, di Brunei dan lainlain, model film seperti apa, movie seperti apa yang hampir pasti ditonton, bahkan ditonton dua kali, tiga kali, empat kali. Mari kita mengadakan penelitian pasar, dengan demikian tidak sia-sia kalau kita memproduksi film dengan investasi yang lumayan...tetapi hampir pasti laku di pasaran. (penekanan saya)

Titik tekan kepada "pentingnya pasar" sampai-sampai harus melakukan riset pasar-bagi perkembangan film Indonesia menunjukkan proses dekonstruksi terhadap jati diri bangsa dalam ekspresi kultural. Mengikuti perspektif Derridean (Derrida, 1989, 1997; Norris, 2002; Zima, 2002; Miller, 2001; Fynsk, 2001), sebagai struktur/konstruksi teks, pada naskah pidato sebelumnya, Presiden SBY menegaskan pentingnya budaya bangsa, tetapi penegasan keutamaan pasar, dengan sendirinya, menghancurkan makna-makna ideal bangsa tersebut. Logika pasar tentu lebih mengedepankan prinsipprinsip nilai tukar sebuah produk di tangan konsumen, sehingga aturan-aturan ketat terkait jati diri bangsa hanya akan menganggu berlangsungnya hukum pasar. Kalaupun ada sineas yang berusaha 'mematuhi' anjuran kultural dan moral rezim, mereka tentu akan menyesuaikan dengan prinsip-prinsip pasar. Dengan demikian, pun bagi rezim negara, pasarlah yang menjadi pertimbangan utama dalam ekspresi kultural, bukan budaya nasional.

Dalam hal produksi kultural, pemerintah memasukkan industri kreatif sebagai salah 
satu prioritas dalam Perpres No. 282008 tentang Kebijakan Industri Nasional. Industri kreatif merupakan "industri yang berasal dari pemanfaatan kreativitas, keterampilan, serta bakat individu untuk menciptakan kesejahteraan serta lapangan kerja dengan menghasilkan dan mengeksploitasi daya kreasi dan daya cipta industri tersebut". Sebanyak 14 sub-sektor industri kreatif juga telah ditetapkan, yaitu industri periklanan, arsitektur, pasar seni dan barang antik, kerajinan, desain, fashion, video film dan fotografi, permainan interaktif, musik, seni pertunjukan, penerbitan dan percetakan, layanan komputer dan piranti lunak, televisi dan radio, serta riset dan pengembangan. Pilihan kebijakan industri kreatif tersebut mengikuti trend serupa di negara-negara maju seperti Amerika Serikat, Eropa, Jepang, dan Australia. Salah satu aspek penting dari industri kreatif adalah menempatkan entitas produk kultural, baik tradisional maupun modern, ke dalam mekanisme industri yang melayani kepentingan pasar, baik nasional maupun internasional.

Kebijakan industri kreatif, dalam konteks kultural, semakin melegalisasi praktik komodifikasi etnisitas yang masih berkembang dalam kehidupan masyarakat lokal. Produk-produk kerajinan bernuansa etnis, barang antik, maupun seni pertunjukan tradisional dikemas-ulang sebagai barang dagangan, atau paket wisata yang bisa, mengikuti pemikiran Venn (2006: 143-144), "memuaskan hasrat partikular posmodern dari masyarakat negara maju" atau masyarakat kota-kota besar Indonesia yang di tengahtengah kesibukan kerja dan keseragaman citarasa modern mulai merindukan kembali nuansa tradisional dan eksotis. Keunikan etnik-etnik di wilayah pedalaman, ritual tradisi, maupun dongeng dan legenda dikomodifikasi dalam produk-produk media, seperti program-program dokumenter, film, dan parodi di televisi. Alih-alih sebagai negosiasi identitas kultural, komodifikasi dan representasi etnisitas dan eskotisme menjadi formula bisnis baru kapitalisme neoliberal yang sangat cair (Comaroff \& Comaroff, 2009). Pun ajaran dan praktik keagamaan yang diyakini memiliki makna-makna keillahian dinarasikan dan direpresentasikan dalam film maupun televisi yang sudah diramu-ulang dengan menggunakan rumusrumus komersil (Einstein, 2008).

Dimasukkannya nilai dan praktik etnisitas di ruang lokal dalam kebijakan industri kreatif memunculkan "titik-titik singgung" dari hal-hal yang semula saling berlawanan. Huggan (2001: 28) menyebut kondisi tersebut sebagai eksotika poskolonial. Di satu sisi, rezim negara pascakolonial di masa Reformasi ingin mempertahankan budaya bangsa sebagai kekuatan untuk menghapus dan melawan efek-efek epistemologis kolonialisme-kuatnya hasrat terhadap keBarat-an. Di sisi lain, mereka terikat kepada pasar global dan kapitalisasi baik dalam bentuk persebaran ide-ide keliyanan kultural dan lalu-lintas perdagangan artifak dan barang yang secara kultural 'terliyankan'. Formasi diskursif keliyanan-eksotisme, ke-primitif-an, dan tradisionalisme-ang pada masa lampau menjadi alat legitimasi praktik kolonialisme (Said, 1978, 1994; Célestin, 1996; Weaver-Hightower, 2007; Brantlinger, 2009; Pennycook, 1998; Gillen \& Ghosh, 2007; Mignolo \& Tlostanova, 2008) di tangan rezim negara dan pemodal industri budaya diramu-kembali sebagai barang dagangan. Mereka, dengan demikian, melakukan 'percumbuan manis' untuk menjalankan "proyek liyanisasi" demi kepentingan baru bernama pasar. Produkproduk kultural menjadi "sirkus penanda" yang memuaskan hasrat eksotis/posmodern sekaligus mendatangkan uang.

Selain penekanan ekonomi pasar dalam konteks produksi kultural, rezim negara secara sadar mengutamakan pembangunan ekonomi sebagai orientasi berpikir dan bertindak secara nasional. Masih dalam pidatonya pada Gerakan Nasional Gotong Royong di 
Pontianak, Presiden SBY mengatakan:

...pemerintah telah meluncurkan yang disebut masterplan atau rencana induk untuk mempercepat dan memperluas pembangunan ekonomi Indonesia. Mengapa itu perlu kita lakukan, percepatan dan perluasan pembangunan ekonomi itu? Karena sesungguhnyakesejahteraan rakyat itu dapat ditingkatkan jika ekonomi nasional, ekonomi seluruh tanah air terus tumbuh dan berkembang, dengan catatan pertumbuhan ekonomi itu bukan hanya sekedar tumbuh tetapi pertumbuhan yang kuat...pertumbuhan yang berimbang, semuanya tumbuh, daerah-daerah tumbuh, pertanian, industri dan jasa tumbuh... kemudian adil, jangan sampai yang miskin tidak berubah kesejahteraannya dari masa ke masa. Kemudian yang keempat, pertumbuhan itu juga berjalan imbang, sustainable, tidak merusak lingkungan. Itulah pertumbuhan ekonomi yang ingin kita wujudkan. (penekanan saya)

Pe-nomor-satu-an "pembangunan dan pertumbuhan ekonomi" dengan asumsi bisa meningkatkan kesejahteraan rakyat merupakan, dalam istilah Barthes (1983), eks-nominasi dari peradaban pasar yang direpresentasikan secara lembut mampu membuat rakyat "sejahtera". Kebijakan masterplan pembangunan ekonomi menunjukkan betapa rezim negara dengan terang-benderang tengah mengarahkan "orientasi kultural secara nasional" dalam hukum ekonomi pasar. Dalam perspektif ekonomi-politik (Marx, 1991, 1992; Lebowitz, 2002; Wood, 2003), segala kebijakan dantindakan ekonomi negara sebagai base-structure akan mempengaruhi keberadaan superstructure yang salah satunya adalah budaya. Artinya, segala hal yang berkaitan dengan persoalan kultural juga diidealisasi mengikuti hukum ekonomi pasar karena bisa membawa kemajuan dan kesejahteraan. Maka dari itu, dengan melihat rezim negara saat ini tengah merekonstruksi budaya nasional baru berbasis ekonomi pasar - sebagai transformasi dari konstruksi serupa di zaman Orba - yang lebih mengadopsi prinsip-prinsip peradaban neoliberal.

Budaya nasional baru berbasis ekonomi pasar, pada dasarnya, lebih mudah menjadi formasi diskursif karena sejak era Orba, kemajuan ekonomi telah menyebar sebagai rezim kebenaran melalui bermacam program, aparat, maupun wacana, dari kota hingga pelosok dusun. Trilogi Pembangunan (Stabilitas Nasional, Pertumbuhan Ekonomi, dan Pemerataan Hasil-hasil Pembangunan) sebagai jiwa dari semua kebijakan pembangunan semasa Orba sangat menekankan pentingnya kemajuan ekonomi yang diidealisasi akan menurunkan angka kemiskinan dan mensejahterakan masyarakat ("Strategi Trilogi Pembangunan", (diunduh dari http:// www.tokoh-indonesia.com/ensiklopedi/s/ soeharto/mti/24/depthnews_07.shtml, 29 September 2011). Bukan hanya aspek industri yang digunakan untuk meningkatkan kekuatan ekonomi nasional, tetapi juga sektor pertanian dengan program intensifikasi dan massifikasi. Akibatnya, masyarakat mulai terbiasa dengan kerja-kerja berorientasi pasar dan uang. Sementara, industri budaya pop yang memberikan hiburan kepada massa dan berorientasi komersil berkembang pesat. Untuk mendukung target ekonomi tersebut dibutuhkan "stabilitas nasional" berupa ketertiban, keamanan, dan integrasi sosial. Wajar kalau pada masa Orde Baru budaya bangsa seperti tepo sliro, tenggang rasa, dan toleransi menjadi formasi utama yang diproduksi secara massif, dari buku pelajaran, ucapan para pejabat, hingga Penataran P-4. Dengan cara itu, rezim berusaha mengeliminir potensi kritik dan resistensi dari warga negara yang bisa mengganggu pembangunan.

Hampir sama dengan rezim Orde Baru, budaya nasional secara esensialis memang tetap muncul dalam pernyatan rezim negara saat ini, tetapi fakta itu tidak untuk menunjukkan kejelian dalam membaca keberantaraan kultural. Kerangka esensialis terhadap budaya nasional, menurut saya, lebih sebagai pencitraan untuk menutupi ketidakberdayaan menghadapi kuasa ekonomi pasar, sekaligus sebagai penanda untuk memberi kesan positif bahwa mereka 
masih memperhatikan aspek budaya. Realitasnya, mereka lebih mengutamakan budaya baru berbasis pasar. Rezim tetap memimpikan (memaksakan?) kuasa-berbasis kultural, tetapi sebenarnya mereka sendirilah yang mendekonstruksi kuasa tersebut dengan merekonstruksi budaya nasional baru menuju peradaban pasar. Maka dari itu, motto Hari Pendidikan Nasional 2011, "Pendidikan Karakter untuk Membangun Keberadaban Bangsa", mungkin selayaknya diganti dengan menghilangkan kata "Bangsa" dan menggantikannya dengan kata "Pasar".

Meskipun oleh banyak pengamat dan akademisi dikritik karena telah menerapkan neoliberalisme, Presiden SBY dalam "Presidential Lecture" pada Indonesia Young Leader Forum 2011, 9 Juni 2011 di Jakarta, menjawab kritik tersebut sebagai berikut:

...ekonomi jalan tengah. Ini my belief...Jalan tengah yang saya maksudkan adalah tentu kita tidak menganut kapitalisme yang fundamental, kita juga tidak menganut yang disebut neoliberalisme. Contohnya, pemerintah tetap berperan di sistem yang amat fundamentalis, peran pemerintah dibatasi, tidak boleh terlalu banyak regulasi, ada policy yang menganggu pasar, subsidi tidak dibenarkan, dibatasi sekecil mungkin. Kita tidak, rakyat kita masih memerlukan subsidi yang terarah, yang tepat sasaran, bukan yang tidak tepat sasaran. Kebijakan masih kita perlukan, pengaturan masih kita perlukan. It means bahwa peran pemerintah masih perlu. Tetapi tidak berarti kaidah-kaidah ekonomi pasar yang bikin efisiensinya, bikin efisiennya sebuah ekonomi tidak kita perlukan, tetap kita perlukan, agar efisien, agar kompetitif, agar kita juga bisa menang dalam persaingan global. (penekanan saya)

"Ekonomi jalan-tengah" atau "ekonomi jalanketiga", pada dasarnya, tetap mengadopsi prinsip neoliberalisme dalam hal kebebasan pasar. Negara memang tidak melupakan "subsidi" dan regulasi untuk 'membela' rakyat, tetapi peran tersebut semakin kecil dari hari ke hari. Pasar-lah yang tetap menjadi panutan karena bisa membuat perekonomian berjalan "efisien", "kompetitif", dan "bersaing secara global".

Pasar memang telah melahirkan apa yang disebut oleh Hardt dan Negri (dikutip Venn, 2006: 136) sebagai kekaisaran baru yang dalam formasi diskursifnya bersifat cair dengan ciri-ciri: (1) ketidakberadaan pusat kuasa dan tidak bergantung pada batasanbatasan yang tetap; (2) mendesentralisasi dan mendeteritorialisasi aparat kuasa yang secara progresif menginkorporasi dunia global dalam keterbukaan untuk memperluas garis batas; dan (3) mengelola identitas hibrid, hirarki yang fleksibel, dan pertukaran beragam melalui aturan berjejaring. Rezim negara saat ini ternyata lebih mengutamakan budaya nasional baru berbasis ekonomi pasar sebagai formasi dirkursif dalam praktik kepemerintahan, termasuk masyarakat, meskipun masih menjalankan sebagian kearifan lokal dan memang lebih menerima pasar sebagai rezim kebenaran. Maka dari itu, budaya bangsa tidak perlu lagi dipaksakan berbasis kearifan lokal secara esensialis dan retrospektif karena sebagian besar "yang lokal" pun - mengikuti "yang nasional" telah bergeser dan berubah dengan mengikuti hukum transaksional pasar.

\section{SIMPULAN}

Dalam kondisi masyarakat yang semakin terpasarkan pada era globalisasi, Schuerkens (2003: 218) dengan perspektif sosiologis memunculkan konsep lokalisme baru, yaitu masyarakat sebenarnya mampu meng-apropriasi pengaruh budaya pasar dan globalisasi ke dalam pemikiran dan tindakan sembari terus menegosiasikan sebagian budaya lokal yang masih eksis untuk kepentingan pemberdayaan lokal. Pemikiran tersebut sejalan dengan konsep transformasi pascakolonial yang ditawarkan Aschroft maupun ambivalensi dan hibriditas kultural yang ditawarkan Bhabha. Namun, konsepkonsep tersebut perlu dibaca dan dimaknaiulang karena peradaban pasar saat ini memberikan kemungkinan dekonstruktif bagi 
"proyek politis" keberdayaan subjektivitas masyarakat pascakolonial. Para penggerak neoliberalisme dengan prinsip cairnya seolah-olah membiarkan rezim negara dan masyarakat terus memproduksi esensialisme kearifan lokal yang seolah-olah masih bisa menjadi kekuatan untuk menegaskan jati diri budaya bangsa dan meresistensi hegemoni oksidentalisme. Para penggerak neoliberalisme, sebenarnya, terus menataulang kekayaan budaya lokal sebagai "ritual dan mata rantai penanda" yang sekedar elok untuk ditonton dan dikonsumsi, bukan untuk dipahami dan diresapi. Boleh saja dipahami dan diresapi, tetapi dengan makna-makna baru yang sudah disesuaikan dengan ideologi pasar.

Ketika wacana dan kebijakan ekonomi yang mendominasi formasi diskursif kepemerintahan, maka kekuatan kultural bangsa hanya akan menjadi "dongeng masa lampau" yang memang perlu didongengkan sekedar sebagai dongeng. Mobilisasi makna kekuatan kultural, dengan demikian, hanyaakan menghasilkan "ketidakberdayaan negosiasi" ketika kebijakan ekonomi pasar lebih dominan dibandingkan kebijakan budaya. Dalam peradaban pasar, konstruksi budaya nasional memang selalu memunculkan dekonstruksi. Akhir dari 'permainan' ini adalah rekonstruksi budaya nasional berbasis ekonomi pasar. Sementara, kearifan lokal, meminjam analogi sepak bola, hanya akan menjadi supporter atau penggembira di pinggir lapangan yang sesekali bisa 'bersorak', 'marah', maupun 'berdemo', tetapi tetap tidak bisa menghentikan transaksitransaksi ekonomi yang akan terus berlanjut sebagai rezim kebenaran.

\section{DAFTAR PUSTAKA}

Alcoff, L.M. and Mohanty.S.P., 2006, "Reconsidering Identity Politics: An Introduction" dalam Linda Martín Alcoff, Michael Hames-García, Satya P. Mohanty, \& Paula M. L. Moya (eds), Identity Politics Reconsidered. New York:
Palgrave Macmillan.

Aschroft, B., 2001, Post-colonial Future: Transformation of Postcolonial Culture, London: Continuum.

Banerjee, I., 2002, “The Local Strikes Back?: Media Globalization and Localization in the New Asian Television Landscape", Gazette: The International Journal for Communication Studies, Vol. 64, No. 6: 517-535.

Bennet, T., 2005, Critical Trajectoris: Culture, Society, Intellectuals, Sydney: Blackwell Publishing.

Bhabha, H. K., 1994, The Location of Culture, London: Routledge.

2002, "Speaking of Postcoloniality, in the Continues Present: A Conversation" dalam David T.Goldberg \& Ato Quayson (eds), Relocating Postcolonialism, Victoria: Blackwell Publishing.

Bhartes, R., 1983, Mythologies, New York: Hill and Wang.

Brantlinger, P., 2009, Victorian Literature and Postcolonial Studies, Edinburgh: Edinburgh University Press.

Canclini, N.G., 1995, Hybrid Cultures: Strategies for Entering and Leaving Modernity (English trans. Christopher L. Chiappari \& Silvia L. López), Minneapolis: University of Minnesota Press.

Célestin, R., 1996, From Cannibals to Radicals: Figures and Limits of Exoticism, Minneapolis: University of Minnesota Press.

Clarke, S., 2005, “The Neoliberal Theory of Society" dalam Alfredo Saad-Filho \& Deborah Johnston (eds), Neoliberalism: Critical Reader, London: Pluto Press.

Collier, S. J., 2009, “Topologies of Power: Foucault's Analysis of Political Governement beyond Governmentality", Theory, Society \& Culture, Vol. 26, No. 6: 78-108.

Comaroff, J. L. and Comaroff. J., 2006, Ethnicity Inc, Chicago: The University of Chicago Press. 
Curran, J., 2002, Media and Power, London: Routledge.

D'Cruz, C., 2008, Identity Politics in Deconstruction: Calculating with the Incalculable, Hampshire: Ashgate Publishing Limited.

Derrida, J., 1997, Of Grammatology Corrected Edition (English trans. Gayatri C. Spivak), Baltimore (USA): The John Hopkins University Press. 1989, "Structure, Sign, and Play in the Discourse of the Human Science" dalam Davis Robert Con \& Ronald Schleifer, Contemporary Literary Criticism: Literary and Cultural Studies, New York: Longman.

Edensor, T., 2002, National Identity, Popular Culture, and Everyday Life, Oxford: Berg.

England, K. and Ward. K. (eds), 2007, "Introduction" dalam Neoliberalization: States, Networks and Peoples, Oxford: Blackwell Publishing.

Einstein, M., 2008, Brands of Faith: Marketing religion in a commercial age, London: Routledge.

Fanon, F., 1963, The Wretched of the Earth (English trans. Constance Farrington), New York: Grove Press.

Faruk, 2007, Belenggu Pascakolonial: Hegemoni dan Resistensi dalam Sastra Indonesia, Yogyakarta: Pustaka Pelajar.

Fynsk, C., 2001, “Derrida and philosophy: acts of engagement" dalam Tom Cohen (ed), Jacques Derrida and the Humanities: Critical Reader, Cambridge: Cambridge University Press.

Foucault, M., 2008, The Birth of Biopolitics, (English trans. Graham Burchell), London: Palgrave Macmillan. 2002, Arkeologi Pengetahuan,

(Terj. oleh H.M. Mochtar Zoerni), Yogyakarta: Qalam.

Gandhi, L., 1998, Postcolonial Theory: A Critical Introduction, New South Wales: Allen \& Unwin Publishing.
Gillen, P. and Ghosh. D., 2007, Colonialism and Modernity. Sydney: UNSW Press.

Gimenez, M. E., 2006, “With a little class: A critique of identity politics", Ethnicities, Vol. 6, No. 3, hlm. 423-439.

Hall, S., 2000, "The Local and the Global: Globalization and Ethnicity" dalam Anthony D. King (et.al), Culture, Globalization, and the World-System: Contemporary Condition for the Representation of Identity, Minneapolis: University of Minnesota Press. 1997, "The Work of Representation" dalam Stuart Hall (ed), Representation, Cultural Representation and Signifying Practices, London: Sage Publication in association with The Open University. 1990, "Cultural Identity and Diaspora" dalam Jonathan Rutherford (ed), Identity: Community, Culture, Difference, London: Lawrence \& Wishart.

Harvey, D., 2007, A Brief History of Neoliberalism, New York: Oxford University Press.

Hesmondhalgh, D., 2008, "Neoliberalism, imperialism, and the media" dalam David Hesmondhalgh \& Jason Toynbee (eds), The Media and Social Theory, London: Routledge.

Huggan, G., 2001, The Postcolonial Exotic: Marketing the Margins, London: Routledge.

Kellner, D., 2003, Media Spectacle, London: Routledge.

Krishnaswawy, R. 2008, "Postcolonial and Globalization: Connections, Conflicts, and Complicities" dalam Revathi Krishnaswawy \& John C. Hawley, The Postcolonial and the Global, Minneapolis: University of Minnesota Press.

Lebowitz, M., 2002, “Karl Marx: The Needs of Capital vs. The Needs of Human Beings" dalam Douglas Dowd (ed), Understanding Capitalism: from Karl Marx to Amartya Sen, London: Pluto Press.

Marx, K., 1992, The Capital: A Critique of Political 
Econnomy Volume 2 (English trans, David Fernbach), London: Penguin Books in association with New Left Review.

1991, The Capital: A Critique of Political Econnomy Volume 3 (English trans. David Fernbach), London: Penguin Books in association with New Left Review.

Mbembe, A., 2001, On Postcolony, Berkeley: University of California Press.

McGuigan, J., 1996, Culture and Public Sphere, London: Routledge. 1999, Modernity and Postmodern Culture, London: Sage Publications.

McNay, L., 2009, “Self as Enterprise: Dilemmas of Control and Resistence in Foucault's The Birth of Biopolitics", Theory, Society $\mathcal{E}$ Culture, Vol. 26, No. 6, hlm. 55-77.

Mignolo, W. D. and Tlostanova. M., 2008, "The Logic of Coloniality and the Limits of Posctoloniality" dalam Revathi Krishnaswamy \& John C. Hawley (eds), The Postcolonial and The Global, Minneapolis: University of Minnesota Press.

Miller, J. H., 2001, "Derrida and literature" dalam Tom Cohen (ed), Jacques Derrida and the Humanities: Critical Reader, Cambridge: Cambridge University Press.

Morton, S., 2007, Gayatri Spivak, London: Routledge.

Norris, C., 2002, Deconstruction: Theory and Practice $3^{\text {rd }}$ Edition, London: Routledge.

Palley, T. I., 2005, “From Keynesianism to Neoliberalism: Shifting Paradigms in Economics" dalam Alfredo Saad-Filho \& Deborah Johnston (eds), Neoliberalism: Critical Reader, London: Pluto Press.

Pennycook, A., 1998, English and The Discourses of Colonialism, London: Routledge.

Quayson, A., 2000, Postcolonialism: Theory, Practice or Process? London: Polity Press.

Radhakrishnan, R, 2003, Theory in an Uneven World, Sydney: Blackwell Publishing.

Said, E. W., 1978/2003, Orientalism: Western
Conceptions of the Orient, London: Penguin Books.

,1994, Culture and Imperialism, New York: Vintage Books.

Sawyer, P., 2006, "Identity as Calling: Martin Luther King on War" dalam Linda Martín Alcoff, Michael Hames-García, Satya P. Mohanty, \& Paula M. L. Moya (eds), Identity Politics Reconsidered, New York: Palgrave Macmillan.

Schuerkens, U., 2003, “The Sociological and Anthropological Study of Globalization and Localization", Current Sociology, Vol. 5, No. 3/4, hlm. 209-222.

Spencer, P. and Wollman.H., 2002, Nationalism:

A Critical Introduction, London: Sage Publications.

Venn, C., 2006, The Postcolonial Challenge: Toward Alternatif Worlds, London: Sage Publications. 2000, Occidentalism: Modernity and Subjectivity, London: Sage Publications.

Weaver-Hightower, R., 2007, Empire Islands: Castaways, Cannibals, and Fantasies of Conquest, Minneapolis: University of Minnesota Press.

Wise, J. M., 2008, Cultural Globalization: A User's Guide, Victoria: Blackwell Publishing.

Wood, E. M., 2002, The Origin of Capitalism: A Longer View, London: Verso.

Zima, P. V., 2002, Deconstruction and Critical Theory (English trans. Rainer Emig), London: Continuum.

\section{Sumber surat kabar dan internet}

Arsuka, N. A., 2008, "Sensor dan Kebebasan”, Kompas, 27 Januari.

Indarto, T., 2007a, “Gonjang-ganjing Perfilman Indonesia", Kompas, 14 Januari. 2007 b, "Mau Berubah ke Mana Film Kita?", Kompas, 11 Pebruari.

"Perpres No. 28 Tahun 2008 tentang Kebijakan Industri Nasional", diunduh dari: http:/ / www.scribd.com/doc/23978616/Perpres- 
No-28, diunduh 29 September 2011.

Soesilo, Bambang Yudhoyono, "Presiden Lecture dengan Tema SBY on Leadership", pada acara Indonesia Young Leaders Forum, Jakarta, 9 Juni 2011, Diunduh dari: http://www.presidensby.info/ index.php/pidato/2011/06/09/1646. html, 11 Juni 2011.

"Sambutan Presiden Republik

Indonesia", pada Acara Gerakan Nasional Bulan Bhakti Gotong Royong ke-8", Pontianak, 31 Mei 2011, Diunduh dari: http://www.presidensby.info/index. php/pidato/2011/05/31/1650.html, 11 Juni 2011.

"Orasi Kebudayaan Nasional Presiden RI" dalam rangka Dies Natalis ke-51 Universitas Diponegoro Semarang, 30 Oktober 2008.

Diunduh dari:http:/ / www.presidensby.info/ index.php/pidato/2008/10/30/1029. htm, 11 Juni 2011.

,"Sambutan Presiden Republik
Indonesia", pada Pembukaan Kongres PARFIXIII,Jakarta,18Mei2006. Diunduh: http://www.presidenri.go.id/index. php/pidato/2006/05/18/255.html, 20 Maret 2010.

"Strategi Trilogi Pembangunan", diunduh dari http://www.tokoh-indonesia. com/ensiklopedi/s/soeharto/mti/24/ depthnews_07.shtml, 29 September 2011.

Wardhana, V. SP, "Sensor Film dan Moral Right", Kompas, 10 Pebruari 2008. 